\title{
KARDIOVASKULINĖ RIZIKA IR FIZINIO AKTYVUMO POVEIKIS ATSKIROMS POPULIACIJOS GRUPEMS. NAUJI ASPEKTAI
}

\author{
Audrè Alonderytė ${ }^{1}$, Robertas Stasys Samalavičius ${ }^{2,4}$, Pranas Šerpytis ${ }^{2,3,4}$ \\ ${ }^{1}$ Vilniaus universiteto Medicinos fakultetas, ${ }^{2}$ Vilniaus universiteto Medicinos fakulteto Klinikinès \\ medicinos institutas, ${ }^{3}$ Vilniaus universiteto ligonine Santaros klinikos, Širdies ir kraujagysliu ligu \\ klinika, ${ }^{4}$ Vilniaus universiteto ligonine Santaros klinikos, Skubios medicinos centras
}

Raktažodžiai: fizinis aktyvumas, kardiovaskulinė rizika, prevencija, fizinis pajègumas, širdies ir kraujagyslių ligos.

\begin{abstract}
Santrauka
Tikslas - aptarti fizinio aktyvumo poveiki širdies ir kraujagyslių ligų rizikos veiksniams atskirose populiacijos grupèse.

Metodika. Atlikta sisteminė mokslinès literatūros apžvalga. Duomenys buvo renkami PubMed duomenu bazèje. Analizuotos tik anglų kalba skelbtos publikacijos, pasirodžiusios ne vèliau nei prieš 5 metus. Analizei atrinkta ir išanalizuota18 viso teksto publikacijų. Rezultatai. Reguliarus fizinis aktyvumas susijęs su rizikos mažinimu susirgti širdies ir kraujagyslių sistemos ligomis [1]. Užsiimant reguliaria fizine veikla, gereja ir tam tikri rodikliai, tokie kaip kūno masès indeksas, arterinis kraujospūdis, cholesterolio bei gliukozès kiekis kraujyje [2]. Idealių kardiovaskulinių komponentų kiekis vaikystejje lemia suaugusiojo sveikatos būklę, todèl labai svarbu skatinti jaunų žmonių fizinį aktyvumą [3]. Fizinis aktyvumas rekomenduojamas ir vyresniems. Šioje populiacijoje fizinis aktyvumas mažina kritimų riziką ir su jais susijusią negalią, gerina bendrą gyvenimo kokybę [4]. Pacientams, sergantiems kardiovaskulinèmis ligomis, rekomenduojamas vidutinio krūvio fizinis aktyvumas, nes didesnio krūvio fizinis aktyvumas neduoda geresnių bendrojo mirtingumo rezultatų[5]. Pastebèta, jog 12 savaičių fizinis aktyvumas padeda pagerinti arba netgi atkurti normalų atsaką i simpatinès nervų sistemos stimuliaciją [1]. Fizinį aktyvumą įtraukiant ị reabilitacijos po širdies ir kraujagysliu ligų programą, sumažeja pakartotinès hospitalizacijos rizika ir mirštamumas nuo kardiovaskulinių ligų [2]. Pacientai, sergantys periferinių kraujagyslių ligomis,
\end{abstract}

mažiau vaikšto ir mankštinasi, todèl vyraujantis sèdimas gyvenimo būdas didina susirgimo širdies ir kraujagyslių ligomis riziką. Svarbu atkreipti demesị ị šią populiaciją, skatinant fizinį aktyvumą periferinų kraujagyslių ligomis sergančių pacientų grupeje [6].

\section{Ivadas}

Širdies ir kraujagyslių ligos (toliau - ك̌KL) buvo ir yra viena iš pagrindinių mirtingumo priežasčių pasaulyje. Didžiausiems ŠKL rizikos veiksniams priskiriama arterinè hipertenzija, hipercholesterolemija, dislipidemija, metabolinis sindromas bei II tipo cukrinis diabetas. Pirminè prevencija yra labai svarbi, norint išvengti arba atitolinti susirgimą ŠKL [7]. Reguliarus fizinis aktyvumas (toliau - FA) mažina mirtingumą, susijusi su kardiovaskulinėmis ligomis bei gerina ivairius rodiklius, tokius kaip kūno masès indeksas (toliau - KMI), cholesterolio kiekis ir arterinis kraujospūdis [2]. Remiantis daugeliu rekomendacijų, vidutinio intensyvumo fizine veikla reikètų užsiimti bent 150 minučių per savaitę, o didelio intensyvumo - bent 75 minutes per savaitę bei mažiausiai du kartus per savaitę atlikti raumenis ir kaulus stiprinančius pratimus $[2,8]$. Pastaruoju metu vis didesnis démesys kreipiamas ị kardiorespiracinị fizinị pajègumą (toliau - KRFP), vertinamą metaboliniais ekvivalentais. Manoma, jog tai gali būti gana tiksli priemonè vertinti pagrindinių širdies ir kraujagyslių sistemos susirgimų riziką [9].Technologijoms tobulëjant, ieškoma vis daugiau būdų motyvuoti žmones užsiimti fizine veikla. Pageidautina, kad visiems galiojančios standartinès rekomendacijos būtų individualizuojamos, siekiant optimalaus rezultato. Individualizuota fizinio aktyvumo veikla skatinama širdies susitraukimų dažnio matavimu išmaniaisiais laikrodžiais fizinio krūvio metu, atsižvelgiant i asmenines žmogaus savybes [10]. Pažymètina, kad bet kokia fizinio aktyvumo forma gerina fizinę bei psichologinę būklę, KRFP ir padeda sumažinti riziką susirgti ŠKL [9]. 
Tyrimo tikslas - aptarti fizinio aktyvumo poveikị ŠKL rizikos veiksniams atskirose populiacijos grupèse.

\section{Tyrimo objektas ir metodika}

Duomenys buvo renkami PubMed duomenų bazèje. Analizei naudoti visateksčiai straipsniai, kai jų pavadinimas, santrauka ar raktažodžiai atitiko apžvalgos tikslą. Analizuotos tik anglų kalba skelbtos publikacijos, pasirodžiusios ne vèliau, nei prieš 5 metus. Analizei atrinkta ir išanalizuota1 8 publikacijų.

\section{Rezultatai ir jų aptarimas}

FA nauda, siekiant mažinti riziką sirgti ŠKL, nagrinèjama daugelyje studijų [11]. Pasitelkiant ịvairias priemones ir klausimynus, bandoma nustatyti optimalų FA kiekị ịvairioms pacientų grupèms [12]. Nors FA yra modifikuojamas veiksnys, tačiau tik nedidelè žmonių dalis skiria jam tinkamą dèmesį [13]. FA naudingas ne tik palaikyti gerą fizinę sveikatą. Jis būtinas ŠKL, nutukimo prevencijai bei sveikatos atkūrimui po ligos [14].

Fizinio aktyvumo nauda paauglių grupèje. 2010 metais Amerikos širdies asociacija pateikè septynis komponentus, apibūdinančius idealią širdies ir kraujagyslių būklę. Tai KMI, nerūkymas, FA, dieta, arterinis kraujospūdis, bendrojo cholesterolio ir gliukozės kiekis kraujyje nevalgius. Idealių kardiovaskulinių komponentų kiekis vaikystejje lemia vėlesnę sveikatos būklę suaugusiam žmogui. Tai labai svarbu, nes paauglystės metu keičiasi žmogaus elgesys ir psichologinè būklè, didèja kūno riebalų kiekis, arterinis kraujospūdis, dèl pakitusios dietos ir ịpročių sutrinka lipidų apykaita, pradedama vartoti tabako gaminius [15]. C. Agostinis-Sobrinho ir kt. atliktame tyrime vertintas paauglių idealus širdies ir kraujagyslių sistemos indeksas ir raumenų būklè po dvejų metų. Gautieji duomenys parodè, kad geresnè raumenų būklè priklausė nuo idealią širdies ir kraujagyslių būklę apibūdinančių kardiovaskulinių komponentų kiekio, todèl svarbu laiku imtis ankstyvosios paauglių ŠKL prevencijos, nes ŠKL gali formuotis dėl paauglysteje vykstančiu gyvensenos ir ipročių pokyčių [3].

Pacientų, sergančių kardiovaskuline liga, grupè. Stimuliuojant sveiko žmogaus simpatinę nervų sistemą šalčio dirgikliu, vainikinès ir miego aterijos dilatuoja. Asmenų, sergančių kardiovaskulinès sistemos ligomis, arba turinčių nemažai ŠKL rizikos veiksnių, šios arterijos ị dirgiklị atsako priešingai - jos susitraukia. Neseniai atliktame B. Buckley ir kt. tyrime vertintas FA poveikis, siekiant atkurti normalu kraujagyslių atsaką. Nors tyrimo imtis nedidele, gauti rezultatai parodè, jog 12 savaičių FA padejo pagerinti arba netgi atkurti normalų atsaką i simpatinès nervų sistemos stimuliaciją. Atsiradus hemodinaminiam stimului FA metu, pagerejja endotelio vientisumas ir funkcija, todèl didejja azoto oksido kiekio prieinamumas ir kraujagyslès išsiplečia [1]. $\mathrm{P}$. Ku ir kt. atliktame tyrime buvo vertinamas FA poveikis sergančiujų kardiovaskulinėmis ligomis mirtingumui. Gauti rezultatai parodé, jog esant vidutinio intensyvumo fizinei veiklai $(1,000-1,999 \mathrm{kcal} / \mathrm{savaitę)}$, bendras mirtingumas sumažèjo 40 proc., lyginant su fiziškai neaktyviais pacientais. Šis FA prilyginamas ilgesniam nei 30 minučių vaikščiojimui didžiają savaitės dienų dalį. İdomu tai, kad dar didesnis FA $(>2,000 \mathrm{kcal} / \mathrm{savaitę})$ neparodè ryškesnio bendro mirtingumo sumažèjimo [5]. FA įtraukiant ị reabilitacijos po ŠKL programą, sumažèja pakartotinès hospitalizacijos rizika ir mirštamumas nuo kardiovaskulinių ligų [2].

Pacientų, sergančių periferinèmis kraujagyslių ligomis, grupè. Periferinių arterijų liga (toliau - PAL) pasireiškia raumenų skausmu fizinio krūvio metu, kuris praeina pailsėjus. Dèl PAL pacientai dažniausiai mažiau vaikšto ir mankštinasi, todèl vyrauja sẻdimas gyvenimo būdas. Dažnai dẻl standžių arterijų sienelių ir širdies autonominès reguliacijos disfunkcijos PAL pacientams stebimas padidèjęs arterinis kraujospūdis. Pagrindinis PAL rizikos veiksnys yra rūkymas. Asmenims, nesergantiems PAL, rūkymas sutrikdo FA ir širdies ir kraujagyslių funkciją [6]. B. Quintella Farah ir kt. atliktame tyrime vertintas rūkymo poveikis simptomine PAL sergantiems pacientams, užsiimantiems fizine veikla. Gauti rezultatai parodè, jog tarp rūkančių pacientų, lyginant su nerūkančiais, vyravo simpatinis autonominis širdies reguliavimas, tačiau nebuvo nustatyta statistiškai reikšmingo ryšio tarp rūkymo ir fizinio pajëgumo [16]. Sergantieji PAL teikia pirmenybę sédimam gyvenimo būdui, o rizika susirgti ŠKL yra padidejusi, todèl reikètų skatinti šios grupès pacientus užsiimti reguliaria fizine veikla. [6].

Vyresnio amžiaus žmonių grupė. Ilgèjant gyvenimo trukmei, daugejja lètinėmis ligomis sergančių asmenų, kurių gyvenimo kokybė yra prasta. Viena iš dažniausių priežasčiu - ŠKL [17]. Dėl šios priežasties reikia imtis prevencijos, kuri sumažintų hospitalizacijų kiekị ir pagerintų gyvenimo kokybę [11]. FA ịvertinti taikomi subjektyvūs (klausimynai) ir objektyvūs (akselerometrai, žingsniamačiai) metodai. M. Kortajerena ir kt. atliktame tyrime pastebeta, jog vyresnių vyrų grupejje abu metodai yra lygiaverčiai, tačiau moterims efektyvesnis objektyvus FA ịvertinimas [18]. A. FraileBermúdez ir kt. atliktame tyrime buvo vertintas vyresnių nei 65 metų moterų FA ir dietos poveikis širdies ir kraujagyslių sistemai. Nustatyta, kad vidutinio lygio FA ir dieta, susidedanti iš baltymais papildyto maisto (pvz.: riešutai, pieno produktai, kiaušiniai), prisidejo prie kardiovaskulinių ligų rizikos veiksnių mažinimo. Pastebèta, jog didelio tankio cholesterolio kiekiui daugiau įtakos turejo ne FA intensyvumas, o jo kiekis [11]. FA integravimas ị kasdienį gyvenimą 
mažina kritimų riziką ir su tuo susijusią negalią vyresnio amžiaus žmonių populiacijoje, gerina bendrają gyvenimo kokybę [4].

\section{Išvados}

1. Ankstyva kardiovaskulinių ligų prevencija bei fizinis aktyvumas paauglystejje lemia geresnę suaugusiujų sveikatą.

2. Vidutinio dydžio fizinis aktyvumas $(1,000-1,999 \mathrm{kcal} /$ savaitę) mažina sergančiųju kardiovaskuline liga mirtingumą.

3. Fizinis aktyvumas padejo pagerinti arba netgi atkurti pacientų, sergančių kardiovaskuline liga, normalų atsaką i simpatinès nervų sistemos stimuliaciją.

4. Fizinio aktyvumo įtraukimas ị reabilitacijos programą po KV ịvykių mažina pakartotinių hospitalizacijų kiekį ir mirtingumą nuo širdies ir kraujagyslių ligų.

5. Fizinio aktyvumo integravimas ị kasdieni gyvenimą mažina kritimų riziką ir su tuo susijusią negalią vyresnio amžiaus žmonių populiacijoje, gerina bendrają gyvenimo kokybę.

\section{Literatūra}

1. Buckley BJR, Watson PM, Murphy RC, Graves LEF, Whyte G, Thijssen DHJ. Carotid artery function is restored in subjects with elevated cardiovascular disease risk after a 12-week physical activity intervention. Can J Cardiol 2019;35(1):23-6. https://doi.org/10.1016/j.cjca.2018.10.015

2. Dickins KA, Braun LT. Promotion of physical activity and cardiac rehabilitation for the management of cardiovascular disease. J Nurse Pract 2017;13(1):47-53.e2. https://doi.org/10.1016/j.nurpra.2016.10.026

3. Agostinis-Sobrinho C, García-Hermoso A, Ramírez-Vélez R, Moreira C, Lopes L, Oliveira-Santos J, et al. Longitudinal association between ideal cardiovascular health status and muscular fitness in adolescents: The LabMed physical activity study. Nutr Metab Cardiovasc Dis 2018;28(9):892-9.

https://doi.org/10.1016/j.numecd.2018.05.012

4. Recchioni R, Marcheselli F, Antonicelli R, Mensà E, Lazzarini $\mathrm{R}$, Procopio AD, et al. Epigenetic effects of physical activity in elderly patients with cardiovascular disease. Exp Gerontol 2017;100:17-27.

https://doi.org/10.1016/j.exger.2017.10.016

5. Ku PW, Chen LJ, Fox KR, Chen YH, Liao Y, Lin CH. Leisuretime, domestic, and work-related physical activity and their prospective associations with all-cause mortality in patients with cardiovascular disease. Am J Cardiol 2018;121(2):177-81. https://doi.org/10.1016/j.amjcard.2017.10.003

6. Gerage AM, Correia MA, Oliveira PML, Palmeira AC, Domingues WJR, Zeratti AE, et al. Physical activity levels in peripheral artery disease patients. Arq Bras Cardiol 2019;113(3):410-416. https://doi.org/10.5935/abc.20190142
7. Martinez-Gomez D, Lavie CJ, Hamer M, Cabanas-Sanchez V, Garcia-Esquinas E, Pareja-Galeano H, et al. Physical activity without weight loss reduces the development of cardiovascular disease risk factors - a prospective cohort study of more than one hundred thousand adults. Prog Cardiovasc Dis 2019;62(6):522-30.

https://doi.org/10.1016/j.pcad.2019.11.010

8. Warburton DER, Bredin SSD. Health benefits of physical activity: a systematic review of current systematic reviews. Curr Opin Cardiol 2017;32(5):541-56. https://doi.org/10.1097/HCO.0000000000000437

9. Ozemek C, Laddu DR, Lavie CJ, Claeys H, Kaminsky LA, Ross $\mathrm{R}$, et al. An update on the role of cardiorespiratory fitness, structured exercise and lifestyle physical activity in preventing cardiovascular disease and health risk. Prog Cardiovasc Dis 2018;61(5-6):484-90 https://doi.org/10.1016/j.pcad.2018.11.005

10. Nes BM, Gutvik CR, Lavie CJ, Nauman J, Wisløff U. Personalized activity intelligence (PAI) for prevention of cardiovascular disease and promotion of physical activity. Am J Med 2017;130(3):328-36. https://doi.org/10.1016/j.amjmed.2016.09.031

11. Fraile-Bermúdez A, Kortajarena M, Zarrazquin I, Irazusta A, Fernandez-Atutxa A, Ruiz-Litago F, et al. Physical activity and dietary habits related to cardiovascular risk in independent community-living older women. Exp Gerontol 2017;92:46-51. https://doi.org/10.1016/j.exger.2017.03.012

12. Lavie CJ, Ozemek C, Carbone S, Katzmarzyk PT, Blair SN. Sedentary behavior, exercise, and cardiovascular health. Circ Res 2019;124(5):799-815.

https://doi.org/10.1161/CIRCRESAHA.118.312669

13. German C, Ahmad MI, Li Y, Soliman EZ. Relations between physical activity, subclinical myocardial injury, and cardiovascular mortality in the general population. Am J Cardiol 2020;125(2):205-9.

https://doi.org/10.1016/j.amjcard.2019.08.031

14. Newland PK, Lunsford V, Flach A. The interaction of fatigue, physical activity, and health-related quality of life in adults with multiple sclerosis (MS) and cardiovascular disease (CVD). Appl Nurs Res 2017;33:49-53.

https://doi.org/10.1016/j.apnr.2016.09.001

15. Henriksson P, Henriksson H, Labayen I, Huybrechts I, GraciaMarco L, Ortega FB, et al. Correlates of ideal cardiovascular health in European adolescents: The HELENA study. Nutr Metab Cardiovasc Dis 2018;28(2):187-94.

https://doi.org/10.1016/j.numecd.2017.10.018

16. Quintella Farah B, Silva Rigoni VL, de Almeida Correia M, Wolosker N, Puech-Leao P, Grizzo Cucato G, et al. Influence of smoking on physical function, physical activity, and cardiovascular health parameters in patients with symptomatic peripheral arterial disease: a cross-sectional study. J Vasc Nurs 2019;37(2):106-12. 
https://doi.org/10.1016/j.jvn.2019.01.003

17. Marzetti E, Calvani R, Tosato M, Cesari M, Di Bari M, et al, SPRINTT Consortium. Physical activity and exercise as countermeasures to physical frailty and sarcopenia. Aging Clin Exp Res 2017;29(1):35-42.

https://doi.org/10.1007/s40520-016-0705-4

18. Kortajarena M, Zarrazquin I, Irazusta J, Gil-Goikouria J, Irazusta A, Hervás G, et al. Objectively and subjectively measured physical activity and its relation to cardiovascular risk factors in older people - which is most appropriate? Maturitas 2019;123:61-6

https://doi.org/10.1016/j.maturitas.2019.01.013

\section{IMPACT OF PHYSICAL ACTIVITY AND CARDIOVASCULAR RISK ON DIFFERENT POPULATION GROUPS, NEW ASPECTS}

\section{A. Alonderytė, R.S. Samalavičius, P. Šerpytis}

Keywords: physical activity, cardiovascular risk, prevention, physical fitness, cardiovascular diseases.

Summary

Regular physical activity is associated with a reduced risk of future cardiovascular disease (1). During normal physical activity also improves certain markers, such as body mass index, cholesterol, arterial blood pressure, and blood glucose (2). The amount of "ideal cardiovascular components" in childhood determines the subsequent state of health in an adult, so it is very important to pay attention and promote physical activity among young people (3). Also, physical activity is recommended for the elderly. In this population, physical activity reduces the risks of falls, associated with disability, as well as improving the overall quality of life (4). In patients with cardiovascular disease, moderate-intensity physical activity is recommended, whereas higher-intensity physical activity does not show better results in terms of overall mortality (5). It was also observed that 12 weeks of physical activity helped to improve or even restore the normal response to stimulation of sympathetic nervous system (1). Also, the inclusion of physical activity in the rehabilitation after cardiovascular disease reduces the risk of re-hospitalization and mortality from cardiovascular disease (2). Patients with peripheral vascular disease have exercise and walk less and the risk of cardiovascular diseases is increased. Because of this reason patients of this group should be considered seriously (6). This article discusses the impact of physical activity and cardiovascular risk on different population groups.

Correspondence to: audre.alonderyte@gmail.com

Gauta 2020-05-14 